of each of the other interested countries (Australia, Japan and the Philippines). At the same time, there will be an executive office with its staff equally balanced internationally. The council will attempt to prepare a final document proposing the specifications of the desired satellite. There is no question but that the satellites will use the UHF band, something that both the FAA and ESRO have agreed on, to the chagrin of commercial international airlines who would prefer a less costly VHF system. The money-about $\$ 150$ million-will be provided by the participating governments.

The advantages will be great. Various governments will not have to bear the expense of proceeding with aeronautical satellite experiments separately and perhaps incompatibly. Eventually separation between aircraft flying routes such as the heavily congested North Atlantic will be substantially reduced. The present methods, in which aircraft cannot be pinpointed more accurately than to within ten miles, requires a horizontal separation of 120 nautical miles and a vertical separation of 2,000 feet. The specifications laid down for the experimental project would permit aircraft to be placed within one half mile of their actual position and to fly as close as 30 nautical miles apart, separated vertically by 1,000 feet.

\title{
What Market for Computers?
}

THESE have been bad times for computer manufacturers in Britain, those owned by British interests and those which operate in Britain as subsidiaries of parent com. panies in the United States. For several weeks now, there has been a steady stream of news of how computer manufacturers have been shedding their labour forces. A week ago, the Department of Trade and Industry provided statistics to show how sales of computers have declined both in Britain and in the British export market. The decline of business has been dramatic. The total deliveries of computers from British manufacturers declined between the last quarter of 1970 and the first quarter of 1971 from $£ 79$ million to $£ 64$ million, a decrease of 18 per cent. This is more than a seasonal effect. Deliveries of computers have risen steadily, quarter by quarter, since 1966 but appear to have reached a peak of $£ 85$ million in the third quarter of 1970 . The decline in the export business has been particularly sharp. Home deliveries fell by ten per cent between the lasts quarter in 1970 and the first quarter in 1971, but export deliveries fell by no less than 33 per cent. In practice, roughly half the lost market consists of machinery which is assembled in Britain from components imported from elsewhere. There was actually a small increase of six per cent in the value of British-made computers delivered to the British market. And if the manufacturers are cast down by their statistics for equipment delivered, they must be even more depressed by the order books, which have been falling since the beginning of 1970 and which, by the beginning of this year, had become so meagre that there is bound to be a further decline in sales as this year wears on.

What has gone wrong? Why has the great fashion for computers been undermined so quickly? In the past few weeks, it has been frequently suggested that the potential purchasers of computing machinery have been discouraged by their own experience of the failure of computers to function properly, or at least as well as the prospectuses for them claim. Is it the case that as with other technical innovations of the past few years-nuclear power, for example - the usefulness of computing machinery has been diminished by optimistic and unattainable promises of what these innovations might accomplish? By all accounts, there is a good deal in this view. After all, the British experience in the past few months is only a more dramatic representation of what is happening elsewhere, particularly in the United States. Small and smallish companies of all kinds are everywhere to be heard complaining that the machinery which they have installed in the past few years has failed to do the job required of it. Core storage turns out to be too small for what it has to remember. Processors turn out to be much slower in practice than they are in theory. The costs of producing software, in any case, substantially incalculable, turn out to be formidably high. And all too often the purchasers of computing machinery discover that their new computer does not help them to reduce the costs of operations or even to undertake fast clerking operations without anxiety.

Salesmen are not solely to blame, although many companies have done themselves a lot of harm by over-selling. There are, however, serious problems of a technical character. Computer people are the first to say how important is the systems approach to practical problems. For an innocent company about to buy a computer for itself, what this implies is that the potential customer has - or should have-a clear idea of what he would like the machine to do but no great concern about the precise manner in which it will function. To be sure, there is much in the view that one of the uncovenanted benefits of acquiring a computer is that it compels those who would use it to understand the business in which they are engaged. But there are limits to what the systems analysts are entitled to claim in this respect. After all, the installation of a new computer system is not an end in itself, or should not be, and it is beyond dispute that the upheaval entailed is in itself a real disincentive. The moral is that manufacturers should as a matter of course sell (or offer to sell) more than a machine-the software should go with it. But it is by now quite clear that the software as sold commercially is often outrageously expensive. If manufacturers want to keep their order books full, they will take steps to see that the machines they sell do actually perform as advertised. Such a goal could bring quite a different structure for the computer industry. As things are, manufacturers have assumed that their profitability is best ensured by apeing the motor car industry and setting up production lines for turning out replicas of more or less identical machines. Although there is undoubted scope for arrangements under which computer complexes can be assembled from smaller parts so as to provide each potential customer with a custom-assembled complex, this is only a beginning. Might it not be more profitable for the manufacturers to find some way of standardizing on software even if this meant that the machinery had to be more sensitively adapted to the customer's needs. 